as is the performance of the visual tasks considered in this paper. Nevertheless, visual efficiency appears to come to its maximum in early adulthood, and, thereafter, to fall off at a greater rate than we realise. This is in keeping with other findings concerning ageing. For example, Bouma ${ }^{1}$ has shown that contrast sensitivity is a function of age, and that it diminishes from the mid-twenties onwards; Mann and Sharpley ${ }^{2}$ have found there is a tendency for the rod field of the dark-adapted eye to contract with advancing age, this tendency becoming apparent at about the age of 30 years; and it has been shown that manual motility begins to decline in the late twenties ${ }^{3}$. Probably many accidents should be attributed to the slowing down of vision as age advances, and it is well known that dissatisfaction with standards of artificial lighting commonly found in workplaces is most prevalent among middleaged and elderly workers. The general tendency for visual performance to decline from a fairly early age, which, in spite of the few subjects studied, is so consistently shown by the results presented in this paper, is certainly subject to individual exceptions. Indeed, individually, some of the subjects of these experiments showed different rates of decline, and probably began their decline at different, though not widely different, ages.

\title{
REFERENCES
}

1. Bouma.-Philips Technical Review, Vol. IX, No. 5, p. 151, 1947.

2. Mann and Sharpley.- Jl. Physiol, Vol. CVI, pp. 301-304, 1947.

3. Miles.--In Cowdry's “ Problems of Ageing," pp. 758-759, 1931.

\section{SIDELIGHTS ON THE INFERIOR OBLIQUE MUSCLE}

BY

\section{J. Ringland ANDERSON}

MELBOURNE

\section{ANATOMICAL $\cdot$ Features}

The relationships of this muscle to the inferior rectus and to the capsule of Tenon and neighbouring orbital fascia require emphasis. These are assuming greater importance as the inferior oblique muscle is directly or indirectly concerned with an increasing number of surgical procedures. The connection between the sheaths of the two inferior muscles and 'Tenon's capsule restricts the effect of division of the inferior oblique muscle. The results of such an operation may vary with the intimacy of such connections and the strength of the check ligaments. 
"English anatomists do not appear to have paid minute attention to this subject." So wrote Lockwood in 1886, 83 years after Tenon's discovery of the capsule that bears his name. If attention has been paid to it since, a perusal of the literature does not make a clear conception obvious. The following description based largely on dissections of refrigerated foetal material appears to the author as accurate (fig. 1).

Tenon's capsule is the membrane surrounding the globe from the limbus to the optic nerve. It varies in thickness, being thickest

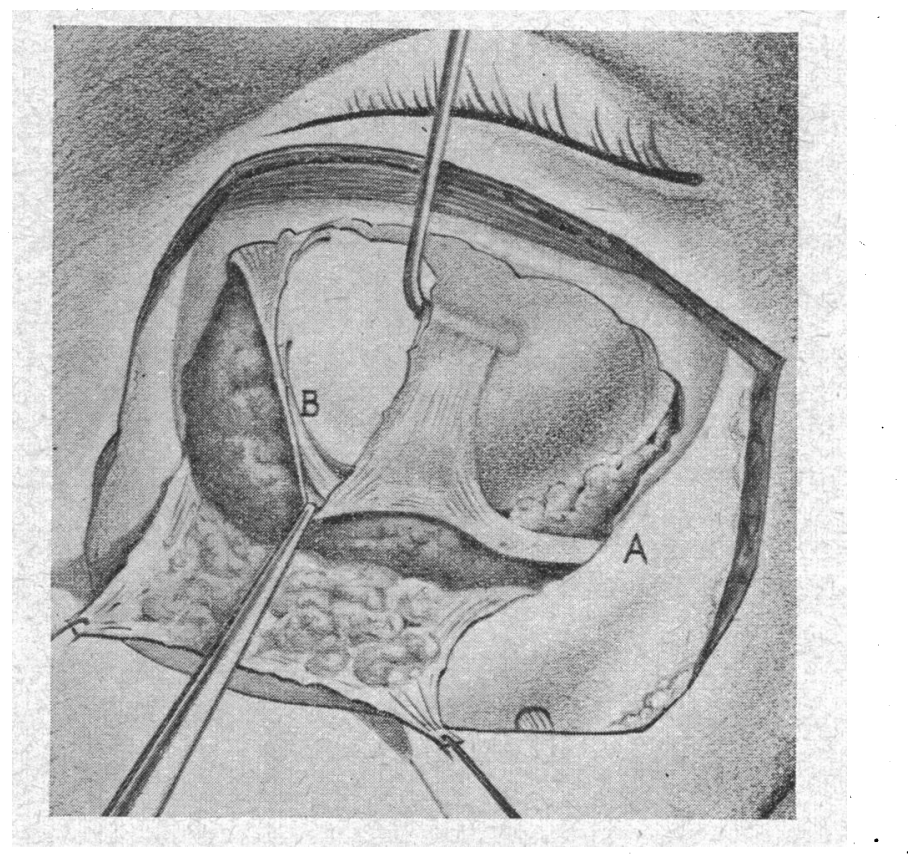

Fig. 1.

The septum orbitale has been opened, a portion of it is seen above, but it is mostly turned down over the zygomatic margin of the right orbit. Over this lies the superficial layer of fat. A portion of Tenon's capsule-the intermembrano is membrane between the inferior and external rectihas been excised exposing margins of these muscles and the insertion of the inferior oblique. The latter is uncovered as forceps draw downwards the suspensory ligament, with which is united the sheath of this muscle. Traction on this sheath shows its union with that of the inferior rectus.

The suspensory ligament is shown approaching its medial and lateral bony attachments. As it approaches the tubercle of Whitnall laterally, it is fused with the septum orbitale, the check ligament of the external rectus and the lateral palpebral ligament. The site for reattachment of the origin of the muscle in W heeler's operation of advancement is marked by A. That for reattachment of the insertion in White's operation of recession is shown at $B$. 
between the equator and the insertions of the muscles. In this area it is loosely attached to the globe by strands of episcleral tissue. In front it is firmly attached.

Each extra-ocular muscle is surrounded by a fine fibrous sheath. In front of the equator the sheaths of adjacent muscles extend towards each other, meet and fuse. These fused extensions form the inter-muscular membrane which encircles the globe in front of the equator. It is reinforced by overlying fibrous tissue.

The sheaths of the inferior muscles unite as they cross at right angles. They and the intermuscular membrane on each side are reinforced as it runs to join the medial and check ligaments at their insertions to the lacrimal and malar bones respectively. This reinforced portion was first described by Lockwood (1886), and is known as the suspensory ligament. The check ligament of the inferior rectus runs forward as a thin layer to the lower eyelid where it is attached between the tarsus and the overlying orbicularis oculi. The sheath of the inferior oblique, or according to Russell, 1948, its inferior layer, is continuous with the suspensory ligament as it runs up to its lateral attachment to Whitnall's tubercle on the zygoma. From the sheath of the inferior oblique a delicate strand of fibrous tissue runs laterally to be attached to the periorbita near the orbital floor. This, as Whitnall suggested, may be inconstant.

\section{Approach to Origin of the Inferior Obligue Muscle}

The origin is adjacent to or rarely more than 5 millimetres from the incisura lacrimalis. The muscle passes laterally and slightly backwards between the inferior rectus and a layer of fat lying on the orbital floor.

One divides the orbicularis oculi and underlying septum orbitale down to the inferior medial border of the orbital margin where it runs obliquely upwards towards the lacrimal sac. If one inserts a muscle hook along the floor of the orbit, turns its point upwards, one engages the muscle and can draw it forwards. It may be necessary to separate it from fat for this ubiquitous packing lies on both its deep and superficial aspects. A myomectomy is performed by holding the muscle in artery forceps and removing the held portion by cutting on each side. of the forceps.

As the inferior oblique muscle leaves its point of origin it is clad with a delicate sheath. It appears as if this muscle becomes attached by its sheath to the suspensory ligament, then runs below the inferior rectus and finally passes obliquely through Tenon's capsule into the space beneath it. This part of the capsule is the portion of the intermuscular membrane that joins the sheath of the external rectus along its lower border. Here the inferior oblique 
muscle lies posterior to the suspensory ligament. The insertion into the sclera is oblique and about 10 millimetres in length, and lies in and below the horizontal meridian. It is under the external rectus, its anterior end being 2 millimetres above the lower level of the external rectus and almost 10 millimetres behind the insertion of this muscle: Fink, 1947. A subcapsular potential space surrounds the terminal portion of the inferior oblique muscle.

\section{Approach to Insertion of the Inferior Oblique Muscle}

As the insertion extends to a point usually 4 millimetres from the fovea the first essential is to rotate the eyeball well upwards and inwards. It may be kept there by a scleral suture. After incision of the conjunctiva one may engage the short tendon below the external rectus before or, more simply, after division of this muscle.

Salzmann, quoted by Whitnall and Fuchs, quoted by Berens, 1943 , stated that the line of insertion often showed gross irregularities, yet Howe, quoted by Krewson (1944), found its site almost constant. Fink, 1947, found insertional variations of the inferior oblique muscle to be second only to those of the superior oblique muscle. In one of his specimens the insertion surrounded the optic nerve. The sheath of the muscle sends extensions that usually join the sheath of the nerve and surround the posterior ciliary nerve and vessels.

Functions OF THE INFERIOR ObliQUe MUSCle.

Though in opposition to Whitnall, Wolff and others it is reasonable to consider the primary action of the oblique muscles to be torsion rather than elevation or depression. This idea was stated by Maddox and Peters and has recently been clarified by Adler (1946). He considered that this muscle was 561 per cent. an extorter and 42.9 per cent. an elevator. It is of interest to recall the term "circumagentes " which was applied by anatomists to the oblique muscles up to the beginning of the 18th Century. Thomas Gibson in the 1688 edition of his "The Anatomy of Human Bodies Epitomized" wrote "The oblique muscles are called circumagentes, winders or rollers about, and amatorii, or amorous, and are in number two." John Brown in 1681 wrote, "These two muscles are called amatorii or the lover's muscles, being as the true messengers of affection, by some they are called circumactores or the rowling muscles, for they do much work in human body." Bartholin in 1655 and Porterfield in 1759 appeared to share this view, whilst $\mathrm{Zinn}$ in 1755 stated that their action was rotatory, but he used the modern titles. Dr. Kenneth F. Russell, who supplied me with this historical information, wrote "If you study a patient with a vertical coloboma when he fixes 
his gaze on some distant object and then slowly move his head laterally-it will be noted that the coloboma will remain in the vertical plane for an appreciable period after the lateral movement has commenced. This amounts to about $5-7^{\circ}$ and represents the rotation of the globe of the eye by the oblique muscles." See also Russell 1932. If we are correct in this view then there is a pair of muscles which primarily rotates vertically, horizontally and circularly or clockwise, respectively.

Though the majority of observers class the inferior oblique muscle as an abductor, Krewson (1944) recently drew attention to Volkmann's measurements which suggested that it was an adductor. He found that the muscle passed anterior to the vertical axis. The muscle is certainly in this position when the globe is rotated. inwards. The diplopia in paralysis would be crossed in the extreme contralateral field if this were so.

The oblique muscles are certainly of less importance than the vertical recti in the vertical plane. The superior rectus is $73 \cdot \tau$ per cent. effective as an elevator and the inferior oblique muscle, but 42.9 per cent.

As is well known the inferior oblique muscles, when the eyeball is in adduction, are frequently found to act in excess as elevators. This may be due to a variety of causes.

\section{Overaction of the Inferior Oblique Muscle}

Causes. These have been discussed in detail elsewhere (Anderson, 1942). Here it is sufficient to classify possible causes as follows :-

(1). Primary overaction due to either asymmetry in the balance or in the insertions of the superior and the corresponding inferior oblique muscles, or to deficient fascial check ligaments or to an oblique insertion of the internal rectus. The presence of an accessory inferior oblique muscle (Whitnall) may explain overaction. Possibly excessive adhesions between the inferior oblique and the inferior or external rectus may act similarly. Chavasse appeared to consider this apparent imbalance in adduction between the oblique muscles to be the rule. It is wise, therefore, to compare the features of these two muscles. See Table 1 .

Reference to this comparison shows that the superior has less vertical purchase than the inferior oblique muscle, because its tendon makes an angle that is $4 \frac{1}{2}$ degrees greater with the median plane than does the inferior oblique muscle. Berens (1936) quoted Verrijp who claimed that the inferior contributed more of its energy to elevation than does the superior oblique to depression. as 42 per cent. is to 37 per cent. 


\begin{tabular}{|c|c|c|}
\hline 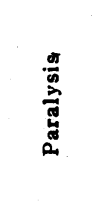 & 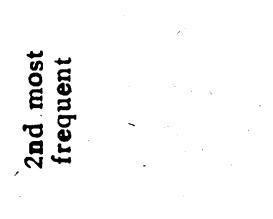 & 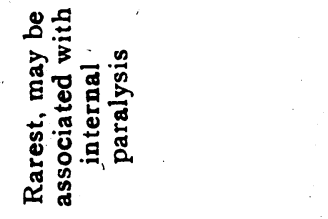 \\
\hline 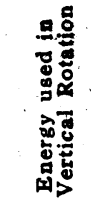 & 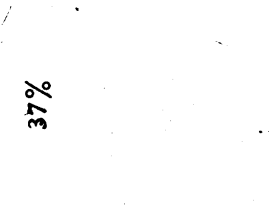 & ஓ̊ \\
\hline 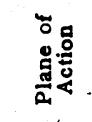 & 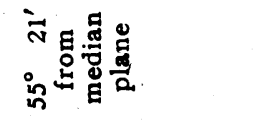 & 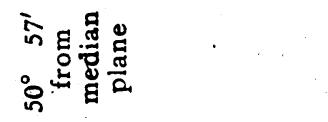 \\
\hline 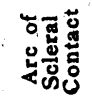 & 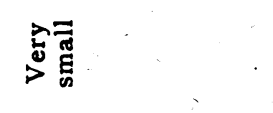 & 呬 \\
\hline 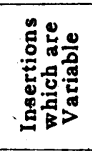 & 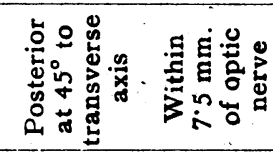 & 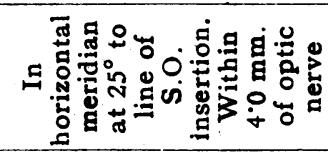 \\
\hline : & . & 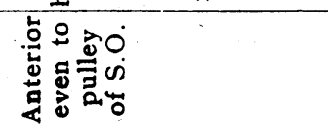 \\
\hline 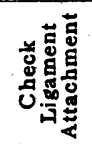 & 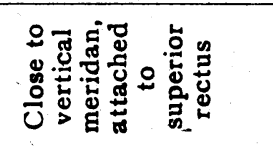 & 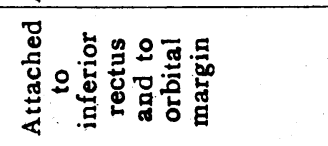 \\
\hline 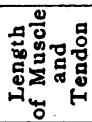 & 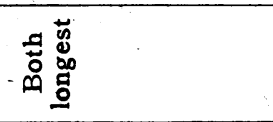 & 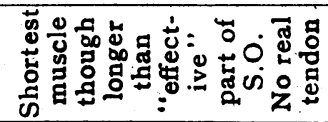 \\
\hline 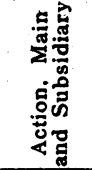 & 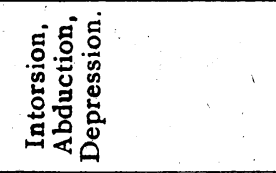 & 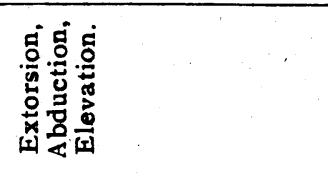 \\
\hline 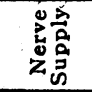 & $\geq$ & $\Xi$ \\
\hline 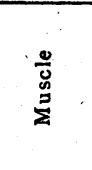 & 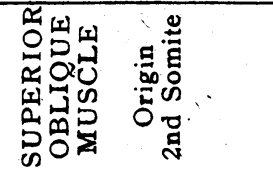 & 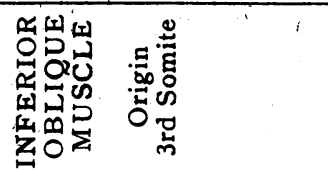 \\
\hline
\end{tabular}


(2). Overaction secondary to paresis of the homolateral superior oblique or the contralateral superior rectus. Overaction is particularly likely to occur in the former condition if the paretic eye is used for fixation. Verhoeff (1941) considered that overaction was always due to paresis of the superior oblique muscle or to hypoplasia of the trochlear nucleus.

There are two schools of thought each based on a difference in method of diagnosis. Each school blamed a different superior muscle paresis as the common cause of overaction. White and Brown (1939) following Duane found weakness of the superior rectus 28 times more frequently than that of the superior oblique muscle. Bielschowsky and his followers believed that paresis of the superior oblique was the most frequent ocular palsy.

The overaction is due, on the one hand, to lack of opposition from the paretic antagonist, the superior oblique muscle, and on the other hand to excessive stimulation following paresis of the yoke muscle, the opposite superior rectus.' As Adler (1946) pointed out, part of the disagreement is due to some authors considering only primary paresis (e.g., Davis, 1944), while others paresis associated with horizontal strabismus as well (White and Brown). Adler found that an isolated primary vertical palsy as studied by Davis (1944) was more commonly of the superior oblique muscle, but that the vast majority of vertical palsies associated with strabismus, as studied by White and Brown, was probably due to a weakness of the superior recti.

In my first series of 127 vertical ocular palsies accompanied by horizontal strabismus the superior rectus appeared to be at fault in 56 per cent. and the superior oblique muscle in 33 per cent. of cases. In my second series of 54 vertical ocular palsies the superior rectus was affected in 48 per cent. and the superior oblique muscle in 27 per cent. when accompanied by horizontal

TABLE II

\begin{tabular}{c|c|c|c|c|c|c}
\hline PARALYSIS & - Sup. R. & Sup. O. & - Inf. R. & - Inf. O. & TOTAL & \\
\hline $\begin{array}{c}\text { With horizontal } \\
\text { strabismus }\end{array}$ & $56 \%$ & $33 \%$ & $7 \%$ & $4 \%$ & 82 & 1st Series \\
\hline 48 & 27 & 18 & 6 & 33 & 2nd Series \\
\hline $\begin{array}{c}\text { Isolated vertical } \\
\text { squint }\end{array}$ & 70 & 27 & 2 & 2 & 45 & 1st Series \\
\hline 5 & 33 & 5 & 5 & 21 & 2nd Series \\
\hline
\end{tabular}

NOTE. In addition there were 16 cases in which the inferior rectus and the contralateral inferior oblique were affected and diagnosis of the initial lesion was not made. 
TABLE III

\begin{tabular}{|c|c|c|c|c|c|c|c|c|c|c|c|c|c|c|c|}
\hline \multirow{3}{*}{ DISORDER } & \multicolumn{15}{|c|}{ MUSCLE DEFECTS } \\
\hline & \multicolumn{4}{|c|}{+ Inf. $O$} & \multicolumn{3}{|c|}{-Inf. $O$} & \multirow{2}{*}{$\underset{\dot{\vec{g}}}{\stackrel{\leftrightarrow}{\vec{g}}}$} & \multirow{2}{*}{$\begin{array}{r}-R \& L \\
\text { Inf } \\
\text { and } \\
\text { an\& } \\
\text { Inf. } R \\
\text { In }\end{array}$} & \multicolumn{3}{|c|}{-S.R } & \multicolumn{3}{|c|}{ - S.o } \\
\hline & $\begin{array}{l}\text { No } \\
\text { H.D. }\end{array}$ & $\mathbf{R}$ & $\mathrm{L}$ & $R \& L$ & $\mathbf{R}$ & $\mathbf{L}$ & $\mid \begin{array}{l}\text { With } \\
- \text { Inf. R }\end{array}$ & & & $\mathbf{R}$ & L & $R \& L$ & $\mathbf{R}$ & L & $R \& \mathrm{I}$ \\
\hline $\begin{array}{l}\text { ALT. } \\
\text { C.C.S. }\end{array}$ & 2 & 4 & 2 & 3. & - & - & 1 & -- & - & 1 & - & - & - & - &.- \\
\hline $\begin{array}{l}\text { Right } \\
\text { C.CS. }\end{array}$ & 19 & 11 & 2 & 8 & - & 1 & 3 & 2 & - & 4 & - & - & 1 & 3 & - \\
\hline $\begin{array}{l}\text { Left } \\
\text { C.C.S. }\end{array}$ & 31 & 10 & 16 & 11 & - & 1 & 2 & 1 & 1 & 1 & 4 & 2 & - & 4 & 1 \\
\hline DIVERGENCE & 7 & 6 & 4 & 1 & - & - & 2 & 3 & 2 & 1 & 6 & - & - & 1 & - \\
\hline $\begin{array}{c}\text { Isolated Vertical } \\
\text { Squint }\end{array}$ & - & - & - & - & - & 1 & - & 1 & 1 & 3 & 8 & - & 3 & 4 & - \\
\hline TOTAL & 59 & 31 & 24 & 23 & - & 3 & 8 & 7 & 4 & 10 & 18 & 2 & 4 & 12 & 1 \\
\hline
\end{tabular}

Eight cases of paralysis of a lateral rectus and five of true or approximately true hyperphoria were included. Fifteen doubtful cases were excluded.

GRAND TOTAL 219 cases with horizontal or vertical strabismus, paretic and so-called concomitant.

67 cases or $30 \%$ had no vertical defect.

78 cases or $36 \%$ showed an overaction of one or both inferior oblique muscles that was the only vertica! defect.

In 47 cases or $22 \%$ the overaction appeared to be secondary to another vertical defect. Three times this was bilateral and associated with palsy of both superior recti and once with bilateral trochlear palsy.

In 3 cases inferior oblique palsy was unilateral, in 8 cases it was associated with weakness of the opposite inferior rectus and the initial palsy was in doubt.

In 4 cases this condition was bilateral and in 7 cases the inferior rectus was paresed.

strabismus. As isolated palsies the superior rectus was affected in 57 per cent. and the superior oblique in 33 per cent. See Tables II and III.

\section{RECOGNITION OF Overaction.}

The overaction may be of the first degree, that is present on ordinary adduction, or of the second degree, present only on forced adduction or of the third degree, that is present only when the eye is looking upwards as well as inwards.

Vertical errors in ocular àlignment are not easy to recognise if slight, or if associated with high degrees of convergence or divergence. Reliance on features that may be used for reference such as margins of lids and the distance from them to the pupils may be misleading. The lids may be asymmetrical. A palpebral aperture updrawn laterally below an abducted eye or down-drawn medially below an adducted eye may suggest elevation of the 


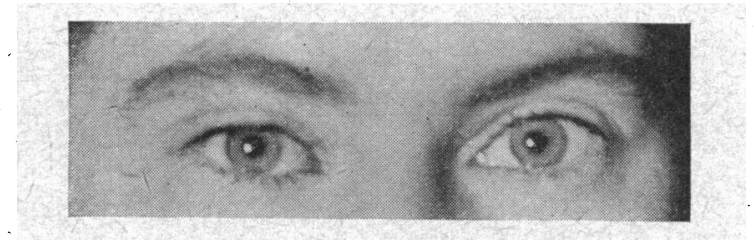

FIG. 2.

An apparent right hypotropia due to the lower level of the right orbit. The true angle was 7 dioptres of right hypertropia. The cause was probably a paresis of the left inferior oblique.

adducted eye. So often facial asymmetry if not congenital soon appears as a testimony to the strain of life. The cover test is always the' safest guide. One eye or even the orbit may be at a different level, and unless recognised may lead to faulty diagnosis

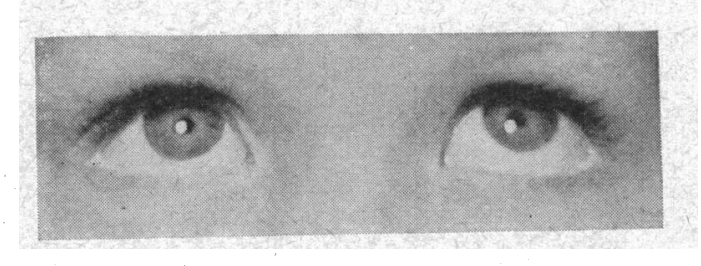

FIG. 3.

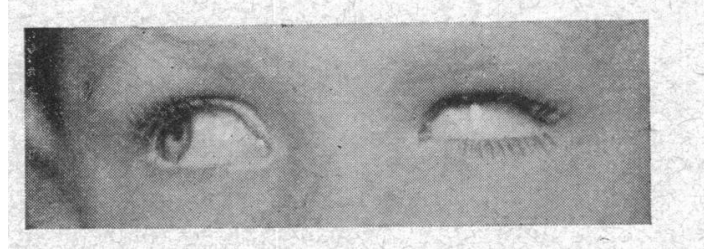

FIG. 4.

Retraction syndrome showing elevation excess on attempting adduction of left eye.

and surgical bewilderment. This was so in the following case :Dorothy A. showed - LIO, - RIR, +RSR, + LSO, by the screen test and the torticollis present suggested that the original lesion was paresis of the left inferior oblique muscle. Prior to this test, however, it was considered that there was a right hypotropia. This was due to the right eye and orbit being on a lower level than the left. There were really 7 dioptres of right hypertropia at a resting angle of -2 . See Fig. 2 . 
Faulty diagnosis was the main reason why eight separate operations were necessary in a patient reported in a recent copy of the American Journal of Ophthalmology:

The excessive elevation on attempted adduction in the retraction syndrome is still a mystery. Figs. 3 and 4 are of a boy with absent adduction and abduction and a slight left hypertropia (3). On attempting adduction the left cornea disappeared under the lid (4). Myomectomy of the inferior oblique was performed twice and the superior rectus was receded without reduction of the elevation excess.

\section{Treatment.}

"A single oblique overaction if strong often necessitates an operation to weaken the muscle. The double oblique overaction can often be ignored provided that it does not interfere with the patient's binocular vision." Sheila Mayou, 1947.

(1). Tenotomy or myomectomy near the origin has been the most common operation. The approach may be cutaneous or conjunctival. It is simple to perform but has certain disadvantages. (1) The result is variable. Very often, however, one has been surprised because the result was so accurate, corresponding with the correction one wished. This was probably so, because the need for correction and the effect of a standardised operation would both vary directly with the degree of overaction present. But because the result has been occasionally, (1) insufficient (Dunnington, 1942; Gifford 1942), (2) excessive (White, 1942), or (3) complicated by cyclotropia (Berens, 1942), there is a tendency to follow White's lead and recede the muscle at its insertion.

Gifford wrote that to prevent reattachment near its origin it was wise to resect 4 millimetres to free the muscle completely from fascial attachments. Otherwise he found that the muscle tended to become reattached near its origin. Neely, 1947, preferred a tenectomy near the origin, and if necessary a tenotomy at the insertion later.

(2). Tenotomy at the insertion. This operation leads to variable results (White 1942) and others, or " almost invariably complete paralysis" (Dunnington, 1942).

(3). Recession, at the insertion as described by White (1942, 1944) and later by Guibor (1944), leads to " much more definite and accurate means of control." Though myomectomy near the origin is usually satisfactory for a unilateral hypertropia over 15 dioptres, in smaller unilateral errors and in bilateral cases recession is indicated. The fibrous bands between this muscle and the 
external rectus require division White (1942). In addition, Guibor (1944), advised division of bands between the inferior oblique and inferior rectus unless one was performing a tenotomy in which case a paralysis would result. The wisdom of dividing them in a recession is doubtful. Berens, 1942, stated that it was not known yet how far to recede the muscle. The tendency was to undercorrect the error. He receded the muscle 9-10 millimetres and as much as 7 millimetres without detaching the external rectus. He had obtained from 4-6 dioptres to total correction of 18 to 20 dioptres. He thought that a recession of 8 millimetres would correct from 5 to 8 dioptres in the primary position. He described a reduction in esotropia when present from one-third to one-half ; in one bilateral case it was from 18 to 5 prism dioptres. White severed the muscle 2 millimetres from the insertion. It has been stated that undue trauma could produce choroiditis near the macula and as a paracentral scotoma. Dunnington. The posterior vortex vein, which is 5.5 millimetres behind the equator, is anterior and medial to the insertion. Care must be taken to avoid the inferior rectus muscle.

Stallard (1946) described a recession controlled by 2 mattress sutures through the ends of the divided muscle. Prangen (1947) attached the inferior oblique tendon on the horizontal meridian and 6-7 millimetres posterior to the mid-point of the insertion of the external rectus. This, he claimed, eliminated all elevation in adduction.

(4). Altered insertions of the horizontal rectus muscles. Bielschowsky, 1945, corrected a high degree of overaction by lowering the insertion of the ipsilateral internal rectus. Foster \& Pemberton, 1946, found that the eye tended to move in the direction of the displacement of the insertion. Half-width raising and resection of the external rectus gave on an average 5.4 dioptres and half width raising of the internal rectus gave half this amount. They considered that marked shortening of the muscle increased the vertical effect.

If the superior oblique was paralysed Wheeler (1935) and later White (1944), sometimes preferred a tuck or advancement, and McGuire (1948) preferred a resection of the paralytic muscle to weakening of the overacting inferior oblique muscle.

\section{Underaction or Paralysis of the Inferior Oblique Muscle}

Bielschowsky found that paralysis was extremely rare. The incidence as found by others is summarised below :- 
TABLE IV

\begin{tabular}{|c|c|c|c|c|c|c|}
\hline $\begin{array}{l}\text { Incidence } \\
\text { among }\end{array}$ & Authors & Series & Sup. R. & Sup. $O$ & Inf. $R$. & Inf. O. \\
\hline \multirow{3}{*}{$\begin{array}{l}\text { Congen. Vertical } \\
\text { Motor Pareses }\end{array}$} & White \& & & Per cent. & Per cent. & Per cent. & Per cent. \\
\hline & Brown, 1939 & 661 & 75 & 2 & 18 & 3 \\
\hline & Duane, 1912 & 107 & 54 & 7 & $\begin{array}{ll}33 & 1\end{array}$ & 6 \\
\hline $\begin{array}{l}\text { All Ocular } \\
\text { palsies }\end{array}$ & Tomizo, 1936 & 150 & $\begin{array}{r}3.3 \\
\text { Ext. R. }\end{array}$ & $29 \cdot 3^{10 \cdot 7}$ & $\begin{array}{c}3.3 \\
\text { Oculomo }\end{array}$ & $\begin{array}{r}0.7 \\
\text { tor } 43 \cdot 3\end{array}$ \\
\hline \multirow[t]{3}{*}{$\begin{array}{l}\text { Unilateral } \\
\text { Vertical palsies }\end{array}$} & $\begin{array}{c}\text { Anderson, } \\
\text { 1st series } 1947\end{array}$ & $150^{\circ}$ & 53 & 27 & 11 & $9^{-}$ \\
\hline & 2nd seriest & 62 & 45 & 26 & 11 & 5 \\
\hline & Hughes, 1943 & 47 & 39 & 6 & 1 & 4 \\
\hline \multirow[t]{2}{*}{$\begin{array}{l}\text { Traumatic } \\
\text { Ocular palsies }\end{array}$} & $\begin{array}{l}\text { Cross, quoted } \\
\text { by Neely }\end{array}$ & 138 & $\begin{array}{c}24 \\
\text { Ext. R. }\end{array}$ & $11^{21 \cdot 5}$ & $\begin{array}{c}2 \\
\text { Int. } R .\end{array}$ & 5 \\
\hline & Neely, 1947 & 54 & $\begin{array}{c}26 \\
\text { Ext: R. }\end{array}$ & $4^{31}$ & 4 & - \\
\hline
\end{tabular}

† NOTE. In this series there were 8 cases with weak inferior rectus and inferior oblique muscles and the initial lesion was not known.

Paresis of the inferior oblique muscle may occur as an isolated palsy when it may be congenital or acquired, or it may be associated with other palsies.

\section{Associated Palsy.}

1. It may be associated with weakness of the contralateral inferior rectus. In paralysis of either muscle a secondary underaction, so called " inhibitional paresis," of the other may occur. If the R. Inf. O. be weak, the ipsilateral antagonist, R.S.O. contracts because of weakened opposition. A reduced stimulus is then required for a given action. Therefore the yoke muscle, L. Inf. R. also will receive a weak stimulus and so appear paretic (Adler, 1946). Just as difficulty in recognising the initial lesion is found in associated paresis of the opposite superior oblique and rectus muscles it also occurs, but less frequently, in disentangling weakness of the inferior oblique and of the opposite inferior rectus muscles. The same guides fortunately hold here. They are :-

(a) Torticollis is more likely if the oblique muscle is affected.

(b) Increase of vertical deviation on forced tilting of the head to the opposite side occurs if the oblique is weak.

(c) The smaller, field of fixation usually belongs to the eye with the primarily affected muscle. 
2. Inferior oblique paresis may also be associated with paresis of the homolateral inferior rectus. When we recall their intimate relationship especially in development this is not a surprising occurrence. Chavasse, 1939.

3. Paresis of the inferior oblique muscle and the homolateral superior rectus may occur together. No elevation of the affected eye will be present. According to White (1942) and Burian (1942), this association is not infrequently seen. The inferior oblique muscle is usually the more paretic.

4. Paresis of the inferior oblique may be associated with that of the medial and the inferior rectus, if the inferior division, and with the superior rectus if both divisions of the third nerve are affected.

5. Paresis of both inferior oblique muscles. This is usually accompanied by underaction of both inferior recti. In my first series this condition was found twice and four times in the second series. Hughes (1943) found paresis of both inferior oblique muscles in one of sixty-nine patients with vertical palsies.

\section{Isolated PALSY. •}

It is the least common isolated oculomotor paralysis (See Table IV).

\section{Congenital Causes.}

These have been summarised recently (Epstein, 1947). There may be :-

(1) Errors of cleavage. The inferior muscles do not completely separate from each other till the 20 millimetre stage.

(2) Aplasia of primitive head cavities.

(3) Aplasia of connections within the central nervous system.

\section{Traumatic Causes.}

Paralysis of the inferior oblique muscle is very rarely the result of the usual forms of trauma. Its production at operation however is possible. The inferior oblique muscle may be injured accidentally during operations for retinal detachment and Gifford's case 22 (1942), is an example of this. White (1943) warned against a similar injury during a recession of the external rectus. This is more likely to occur if this muscle has been operated on previously. It has been claimed that hypertopia following such an operation may be due to such an injury.

\section{Treatment.}

The successful methods of treatment may be summarised as follows :- 
1. To Strengthen the Affected Muscle.

(a) Advance at bony origin. Wheeler 1935, Kirby 1946, preferred this and reported cases. Chavasse thought this was the wisest treatment. With the courage based on accurate observations that characterised him, J. M. Wheeler led this attack on the paralysed muscle itself. He advanced the muscle over the orbital margin and using two sutures attached it to the periosteum of the maxilla. He obtained satisfactory results, 1935. $\mathrm{He}$ and White agreed, however, that in paralysis this alone was inadequate.

(b) "Advance" or tuck at insertion and if inadequate perform recession of contralateral superior rectus. (White, 1942, 1943, 1945; Dunnington, 1942). White, however, stated that neither splicing at the insertion nor tucking at the origin gave as large a correction as Wheeler's operation which could correct from $30^{\circ}$ to $50^{\circ}$ according to which eye was fixing.

(c) Resection at insertion. Berens and Loutfallah (1943) used a single mattress suture. Wagman (1945) preferred three sutures. 2. To Weaken Contralateral Yoke Muscle.

(a) Duane suggested tenotomy of the contralateral superior rectus.

(b) Recession of this muscle was used by Kirby (1946), Dunnington (1929), Berens, Paine and Kern (1935), Sheppard (1947), and others. Berke claimed that this operation might widen the palpebral aperture and unduly restrict elevation.

3. To Weaken Homolateral Antagonist Muscle.

(a) Tenotomy of homolateral superior oblique. Dunnington stated that it was not feasible to weaken this muscle and White thought he had never seen an indication for its tenotomy. Berke (1947), however, claimed that this was the best treatment for overaction of the superior oblique muscle.

(b) Recession of trochlea. Hughes (1944) and Hughes and Bogart (1942), reported 8 cases. Wagman (1945) thought that though their cases were mainly due to overactive superior oblique muscles, the initial lesion in some was probably paresis of the inferior oblique.

\section{Conclusion}

Careful dissection, a study of function, and accurate clinical observation must precede accurate diagnosis and without accuracy in diagnosis satisfactory treatment is unlikely. The significance of slight errors in ocular movements is obscure. They do not all mean a previous lesion or even a minor rôle in producing strabismus. Their frequency in normal cases is as yet unknown.

The underaction of a contralateral antagonist may be diagnosed 
as a primary lesion and the initial paresis missed or given a secondary rôle. This applies to a superior or inferior rectus and its corresponding opposite superior or inferior oblique muscle. As my observations increase my diagnosis of palsy of the superior rectus appears less frequently. Its frequency fell from 53 per cent. in my first series to 45 per cent. in my second series. One must be careful in diagnosing it (1) unless associated with ptosis or weakness of another muscle supplied by the third nerve, ( 2 ) if torticollis to one shoulder is marked and increases on tilting the head to the opposite side, or (3) the projection field of the suspected eye is smaller than that of its fellow.

One must be careful to correct large horizontal errors before tackling most vertical defects. The latter may become negligible or require only an unilateral operation. Sometimes after an operation on one overacting inferior oblique, if both had been overacting, there may be an apparent increase in the overaction of its fellow.

It may become possible to vary reattachment to correct sometimes more torsion and sometimes more elevation according to the particular need of the patient. Wheeler, 1935, in shortening the superior oblique muscle reattached it farther forwards to correct torsion, and backwards to correct elevation.

I would express my gratitude to Dr. H. F. Bettinger of the Women's Hospital, Melbourne, for supplying material for dissections, to Dr. K. F. Russell of the Department of Anatomy, Melbourne University, for advice and help with these, and to Rev. W. M. Rolland for his skill and patience in drawing.

\section{BIBLIOGRAPHY}

AdLer, F. H.- " Physiological Factors in Differential Diagnosis of Paralysis of the Superior Rectus and Superior Oblique Muscles." Arch. Ophthal., Vol. XXXVI, p. 661, Dec, 1946.

Anderson, J. R.- “Ocular Vertical Deviations," Brit.Ji. Ophthal., Monograph Supplement XII, p. $61,1947$.

BERENS, C.- "The Eye and its Diseases." Saunders. Philadelphia, p. 842, 1936.

BERENS, Discussion. J. W. White's Article. Trans. Amer. Ophthal. Soc., Vol. XL, p. 118, 1942.

Berens, C. and Loutfallah, M-." Resection of the Left Inferior Oblique Muscle at its Scleral Attachment for Postoperative Left Hypertropia and Pseudoptosis." Amer. Jl. Ophthal., Vol. XXVI, p. 528, May, 1943.

BERENS, C., PAYNE and KERN. - "Orthoptic" Training and Surgery in Hyperphoria and Hypertropia combined with Lateral Deviations." A mer. Jl. Ophthal., Vol. XVIII, p. 508, June, 1935.

BERKE, R. N.- "Tenotomy of the Superior Oblique for Hypertropia." Arch. Ophthal., Vol. XXXVIII, p. 605, November, 1947.

Bielschowsky. A. - Lectures on Motor Anomalies, Dartmouth College Publications, New Hampshire, 1945.

Burian. H. M.-Discussion. Arch. Ophthal., Vol. XXVII, p. 370, February, 1942.

Chavasse, F. B.- "Worth's Squint." Bailliére, Tindall and Cox, London. 7th Edition. 1939. 
DAvis, W. T.-." Paresis of Right Superior Oblique and of Left Superior Rectus Muscles." Arch. Ophthal., Vol. XXXII, p. 372, November, 1944.

DuAne. A.-" Congenital Deviations of the Eyes." Trans. Amer. Ophthal. Soc., Vol. XII, p. 981, 1912 .

DunNington. J. H. "Tenotomy of the Inferior Oblique." Trans. A mer. Ophthal. Soc., Vol. XXVII, p. 227, 1929.

- Discussion:- " Recession of the Inferior Oblique Muscle." Arch. Ophthal., Vol. XXIX, p. 1034. June, 1943.

EPstein.- “Congenital Vertical Motor Pareses." Arch. Ophthal., Vol. XXXVII, p. 371, March, 1947.

FINK, W. H. - "A Study of the Anatomical Variations in the Attachments of the Oblique Muscles of the Eyeball. Trans. Amer. Acad. Ophthal. and Otolaryn., p. 500, May, 1947.

Foster, J. and PEMBERTON, E. C.- "The Effect of Operative Alterations in the Height of the External Rectus Insertion." Brit.Jl. Ophthal., Vol. XXX, p. 88, February, 1946.

GIFFORD, S. R.- "Position of Muscles after Operation for Strabismus." Arch. Ophthal., Vol. XXVII, p. 443, March, 1942.

Guibor, G. P.- "Recession of the Inferior Oblique Muscle." Amer.Jl. Ophthal., Vol. XXXVII. p. 371, March, 1944.

Hughes, W. L.- "Recession of the Trochlea." Amer. Jl. Ophthal. Vol. XXVII, p. 1123 , October, 1944 .

Discussion. "Recession of the Inferior Oblique Muscle." J. W. White. Arch. Ophthal. Vol. XXIX, p. 1033, June, 1943.

Hughes, W. L. and BogaRT, D. W.-"Recession of the Trochlea in Overaction of the Superior Oblique." Amer. Jl. Ophthal., Vol. XXV, p. 911, August, 1942.

KIRBY, D. B.- "Paralysis of Ocular Elevation with and without Ptosis." Arch. Ophthal., Vol. XXXV, p. 199, March, 1946.

Krewson, W. E.- "Comparison of the Oblique Extraocular Muscles." Arch. Ophthal., Vol. XXXII, p.'204, September, 1944.

Lockwood, C. B.-" The Anatomy of the Muscles, Ligaments and Fasciae of the Orbit, including an Account of the Capsule of Tenon, the Check Ligaments of the Recti and of the Suspensory Ligaments of the Eye. Jl, of Anat. and Physiol., Vol. XX, p. 1, 1886.

Mayou, Sheria.-." Case Notes of Special Interest." Brit. Jl. of Orthoptics, Vol IV, p. 150,1947 .

McGuire, W. P.-"The Surgical Correction of Paresis of the Superior Oblique." A mer, Ji. Ophthal., Vol. XXXI, p. 65, January, 1948.

NEELY, J. C. “The Treatment of Traumatic Diplopia." Brit. Jl. Ophthal., Vol. XXXI, p. 581, October, 1947.

Prangen, A.- "Surgery of the Extraocular Muscles. Amer. Jl. Ophthal., Vol. XXX, p. 1161, September, 1941.

RusselL, K. F.- "The Rotation of the Eyeball." Med. Jl. Australia, September 17, 1932. Personal communication, 1948.

SheppaRD, A. W.-Discussion. Amer. Jl. Ophthal., Vol. XXX, p. 1124, September, 1947.

Stallard, H. B.- "Eye Surgery," John Wright, Bristol, p. 220, 1946.

Томіzо.- "Die Aetiologie und Statistik der Augenmuskellahmungen," Quoted Jap. Jl. Med. Science, Vol. XI, part 2, p. 646, 1936.

VERHOEFF, F. H.- "Oćlusion Hypertropia." Arch. Ophthal., Vol. XXV, p. 780. May, 1941.

Wagman, O. H.- "Resection of the Inferior Oblique Muscle in Hypertropia." Amer.Jl. Ophthal., Vol. XXVIII, p. 1226, November. 1945.

WheEler, J. M. - "Advancement of the Superior Oblique and Inferior Oblique Ocular Muscles.' Amer. Jl. Ophthal., Vol. XVIII, p. 1, January. 1935.

WHITE, J. W.- "Surgery of the Inferior Oblique at or near the Insertion." Trans, Amer. Ophthal. Soc., Vol. XL, p. 118, 1942. "The Choice of the Fixating Eye in Paralytic and Non-paralytic Strabismus." Amer. $J l$. Ophthal., Vol. XXVII, p. 817, August, 1944. Discussion. Trans: Amer. Ophthal. Soc., Vol. XLIII, p. 218, 1945.

White, J. W. and BRown, H. W.- Occurrence of Vertical Anomalies Associated with Convergent and Divergent Anomalies." A rch. Ophthal., Vol. XXI, p. 1000 , June,1939. 